\title{
Uma análise teórico- política decolonial sobre o conceito de moda e seus usos
}

Heloisa Helena de Oliveira Santos

Doutora, Instituto Federal do Rio de Janeiro / heloisahosantos@gmail.com Orcid: 0000-0002-8551-7564 / lattes 


\title{
Uma análise teórico-política decolonial sobre o conceito de moda e seus usos
}

\begin{abstract}
RESUMO
A partir de uma perspectiva pós-colonial/decolonial, a proposta do artigo é questionar o conceito ocidental de moda e seus possíveis usos. Entendemos que o conceito de moda pode ser utilizado como uma noção dentro do aparato ideológico colonial que busca desautorizar a relação das sociedades não ocidentais com o tempo ao afirmar que estas últimas não tem moda porque pouco mudam seu vestuário, ou como o colonizador prefere chamar, sua indumentária ou costume. Este tipo de binarismo, no caso "moda X costume", engessa, como aponta Quijano (2005), as sociedades não ocidentais e fornece ao Ocidente o status ideológico do movimento, da capacidade de se modificar, renovar e, por que não, evoluir (em um sentido evolucionista mesmo), pois como aponta Said (2007), o colonizador, em seu lugar de autoridade, entende que lhe cabe "ler" o colonizado e traduzir a cultura do mesmo para si próprio.
\end{abstract}

Palavras-chave: moda. Decolonialidade. Capitalismo. 


\title{
A decolonial theoretical-policy analysis on the fashion concept and its uses
}

\begin{abstract}
From a postcolonial / decolonial perspective, the purpose of the article is to question the western concept of fashion and its possible uses. We understand that the concept of fashion can be used as a notion within the colonial ideological apparatus that seeks to disallow the relationship of nonwestern societies with time by stating that the latter has no fashion because little change their clothing, or as the colonizer prefers to call it, your costume. This type of binary, in the case of "fashion X costume", engenders, as Quijano (2005) points out, non-Western societies and provides the West with the ideological status of the movement, its ability to change, renew itself and, why not, evolve (in an evolutionary sense). As Said (2007) points out, the colonizer, in his place of authority, understands that it is up to him to "read" the colonized and to translate his culture to himself.
\end{abstract}

Keywords: fashion. Decolonial. Capitalism. 


\title{
Un análisis teórico-político descolonial del concepto de moda y sus usos
}

\begin{abstract}
RESUMEN
Desde una perspectiva poscolonial / descolonial, el propósito del artículo es cuestionar el concepto occidental de moda y sus posibles usos. Entendemos que el concepto de moda se puede usar como una noción dentro del aparato ideológico colonial que busca no permitir la relación de las sociedades no occidentales con el tiempo al afirmar que estas últimas no tienen moda porque cambian poco su ropa, o como el colonizador prefiere llamarla, Su vestido o costumbre. Este tipo de binarismo, en el caso del "traje de moda $X$ ", plaga, como señala Quijano (2005), las sociedades no occidentales y proporciona a Occidente el estatus ideológico del movimiento, la capacidad de modificar, renovar $y$, por qué no, evolucionar (en un sentido muy evolutivo), porque como dice Said (2007), el colonizador, en su lugar de autoridad, entiende que depende de él "leer" a los colonizados y traducir la cultura de los mismos a sí mismo.
\end{abstract}

Palabras clave: moda. Decolonialidad. Capitalismo. 


\section{INTRODUÇÃO}

"African diasporic theory offers a way to break out of oppositional thinking and evolutionary notions of progress. African American epistemologies - in conversation with other African diasporic thought - can be characterized as moving beyond either/or frameworks to 'both/and' ways of knowing." (KAISER; MCCULLOUGH, 2010, p. 361)

Podemos dizer que o vestir é uma ação encontrada nas mais diferentes culturas. Ainda que percebido de maneiras diferenciadas, vestir-se é uma ação social no sentido weberiano e mesmo quando nus, estabelecemos uma relação com o vestir. Mas o mesmo pode ser dito sobre a moda? O conceito de moda é debatido desde Simmel que iniciou uma discussão sobre a mesma ainda no século XIX, mas até hoje, ainda é um tema controverso em alguns pontos. Se entendermos que a moda envolve uma relação específica com o tempo e com a mudança ou com um desejo permanente de novidades, é possível que questionemos a existência de moda em alguns contextos, especialmente se considerarmos, a partir de uma perspectiva de senso comum, que a mudança é uma característica própria do Ocidente. Contudo, se avaliarmos o próprio conceito de tempo e mudança como construções ocidentais, é possível discutirmos mesmo a própria noção de moda.

Considerando estes fatores, pretendo, neste artigo, analisar a noção de moda a partir de uma discussão sobre o vestuário em sociedades não ocidentais. Tomando uma perspectiva pós-colonial/decolonial, a proposta é questionar o próprio conceito ocidental de moda e seus usos por pesquisadores. Entendemos que o conceito de moda pode ser utilizado como mais uma noção dentro do aparato 
ideológico colonial que busca desautorizar a relação das sociedades não ocidentais com o tempo ao afirmar que estas últimas não tem moda porque pouco mudam seu vestuário, ou como o colonizador prefere chamar, sua indumentária ou costume. Trata-se de uma desconstrução, por meio de uma desvalorização sistemática, dos diversos sentidos fornecido por cada povo a sua realidade: aquilo que genericamente denominamos cultura - cultura esta que Segato (2012 e em outros trabalhos) demonstra ser nada mais do que um trabalho de congelamento dos sentidos de existência dos povos pelo colonizador - é permanentemente desqualificado através da destruição dos "sistemas de referência" (FANON, 2011) destas sociedades. Este tipo de binarismo, no caso "moda X costume", engessa, como aponta Quijano (2005), as sociedades não ocidentais e fornece ao Ocidente o status ideológico do movimento, da capacidade de se modificar, renovar e, por que não, evoluir (em um sentido evolucionista mesmo).

Outro ponto interessante deste processo de desautorização das sociedades ocidentais é a própria noção de criação, "inspiração" e cópia, muito utilizadas pela moda ocidental: enquanto os grandes estilistas europeus se inspiram e criam a partir da moda africana ou, pensando na diáspora, nos guetos e ruas, ou ainda, trazendo para o caso brasileiro, indígena, ribeirinho e outros, aos povos "sem moda" - ou até "sem história" (SAHLINS, 2003) cabe apenas, em resposta, copiar. Como aponta Said (2007), o colonizador, em seu lugar de autoridade, entende que the cabe "ler" o colonizado e traduzir a cultura do mesmo para si próprio, pois o colonizado seria incapaz de perceber o valor em sua própria cultura. Este artigo se debruça, assim, sobre o próprio conceito de moda, a discussão teórica sobre o mesmo e seus possíveis usos como parte do processo político-ideológico colonial. Pretendo apontar uma 
abordagem para os estudos de moda no Brasil que a politize, buscando discutir as percepções de que a moda seria algo único e próprio do Ocidente e as consequências deste tipo de percepção. Considero que não serei capaz de encerrar neste artigo - e sequer tenho esta pretensão -, a discussão sobre este conceito e tenho mesmo dúvidas se vou acertar o caminho das análises, mas acredito ser pertinente trazer este tema para a discussão a fim de refletir sobre os caminhos das reflexões sobre a moda no Brasil. Feita esta apresentação, sigamos para as discussões.

O artigo estará dividido em três seções, além desta introdução: na primeira parte, faremos uma breve síntese sobre as teorias sobre moda. Na sequência, trataremos das discussões pós-coloniais e decoloniais pertinentes à discussão que encaminharemos na terceira seção, quando realizamos uma análise sobre o conceito de moda à luz dessas teorias.

\section{A moda como campo de estudos}

As primeiras análises sobre a moda como um fenômeno social foram iniciadas, como apontado acima, no século XIX, tendo como autores centrais para o debate Herbert Spencer, Gabriel Tarde, George Simmel e Thorstein Veblen. De acordo com Rainho (2002, p. 20), "Os trabalhos desses autores foram tão inovadores que, ainda hoje, as questões apontadas por eles são retomadas nos estudos dedicados à moda. Em linhas gerais, suas obras giram em torno da discussão das diferenças entre moda e costume, da abrangência da moda e de duas características que regulam sua existência: a imitação e a distinção".

No Brasil, o primeiro trabalho a ter a moda como tema de pesquisa em uma pós-graduação foi desenvolvido na USP por Gilda de Mello e Souza. É consenso nos estudos sobre 
moda no Brasil, a existência de duas percepções sobre a moda como parte das sociedades. A maior parte, senão todas as pesquisas que abordam a moda, revisam as primeiras reflexões sobre o tema e apontam que os autores clássicos que analisaram a moda ou 1) a percebem como um uma forma geral que se encontra em todas as civilizações e que atinge todas as instituições sociais ou; 2) entendem a moda como um fenômeno iniciado no século XIV, tendo seu ápice durante o século XIX. Não me deterei aqui em retomar esta discussão que já foi muito bem feita não apenas por Rainho (2002), mas, como apontado, por diversos trabalhos. Gostaria, no entanto, de discutir brevemente dois pontos.

Em primeiro lugar, considerando a moda um fenômeno sempre existente e amplamente difundido ou algo particular e iniciado com a individualização das sociedades no século XIV, todos os autores afirmam que a moda é algo próprio do Ocidente: Gabriel Tarde, por exemplo, aponta a existência da moda em diversos momentos do Ocidente, como na Grécia Antiga, na Florença do século XV e na Paris do século XIX. Além disso, os conceitos de individualidade e de classe, dentre outros, utilizados com frequência para caracterizar o surgimento do fenômeno moda, por geralmente estarem associados ao tipo de sociedade que se desenvolve no Europa, restringem a discussão sobre a moda na sociedade ocidental burguesa capitalista exclusivamente, pois tanto a noção de indivíduo quanto a de classe remetem a esse contexto. O que desejo indicar, deste modo, é que não importa o modo como a moda é entendida: seu surgimento e desenvolvimento são sempre próprios e singulares à sociedade Ocidental moderna.

Em segundo lugar, como um desdobramento deste primeiro ponto, temos a questão da cópia: às sociedades fora do eixo Ocidental, assim como às classes populares, cabe apenas à imitação. Um exemplo são as camadas 
enriquecidas do Brasil colonial - elas mesmas fora do eixo Ocidental e inseridas à margem do capitalismo mundial que buscavam, por meio da civilidade e das roupas europeizadas (FREYRE, 2006; RAINHO, 2002), se destacar dos outros estratos sociais que aqui habitavam e se aproximar dos europeus - povo no qual se identificavam e reconheciam - , que eram entendidos como aqueles que de fato estariam inseridos em uma lógica de moda. Não autorizados como povo e cultura, qualquer criação que aqui possa ter se desenvolvido não é considerado como válido e todo vestuário aqui utilizado sempre será percebido como cópia. Assim, não importa a leitura que se faz sobre a moda, o conceito é construído em torno de uma particularidade Ocidental em oposição a uma incapacidade criativa dos povos colonizados: incapacidade esta necessária para a própria afirmação da criatividade e capacidade de inovação das sociedades ao Norte. Cabe mesmo perguntar se o olhar do pesquisador colonizado seria capaz de identificar particularidades no Brasil ou na África, caso a houvessem.

Desta maneira, entendemos que a noção de moda está inserida dentro de um corpus conceitual mais amplo, próprio do âmbito colonial, que incluiria uma série de binarismos que constituem aquilo que o grupo colonialidade/modernidade liderado por Quijano denomina colonialidade do saber. Como parte do processo de criação do Ocidente em oposição ao não-Ocidente, um conjunto de noções foi constituída e disseminada a partir do centro difusor de conhecimento europeu. Vamos nos deter nesta discussão na próxima seção, pois ela é fundamental para o questionamento do conceito de moda que estamos propondo neste texto.

\section{A colonialidade do saber: reflexões pós-coloniais e decoloniais}


A fim de iniciar esta seção, é relevante indicar que certa inquietude sobre o conceito de moda acompanha esta autora desde 2015, quando a mesma questionou a noção no capítulo teórico de sua tese que versava sobre a moda como parte da economia criativa. Este incômodo, contudo, permaneceu silenciado até muito recentemente. De um lado, porque o excesso de trabalho não permitia que a autora tivesse tempo para retomar a reflexão sobre o tema; segundo porque foi necessário ler o artigo "Colonialidade do poder, eurocentrismo e América Latina" de Aníbal Quijano para que aquela inquietação voltasse a despertar.

A situação colonial é tema de reflexão de historiadores, sociólogos e outros profissionais das ciências humanas. Durante muitas décadas, era privilégio da metrópole o lugar de reflexão sobre as sociedades antes colonizadas. Em meados do século $X X$, especialmente após a descolonização da África, iniciou-se o movimento de questionamento deste lugar: é sabido que já se produzia conhecimento de alto nível e qualidade nas colônias, contudo ocorre um processo de indagação sobre o modo mesmo de produção do conhecimento pelo ex-colonizador sobre as colônias, de um lado, e uma apropriação da produção de conhecimento sobre si e sobre a própria história pelos povos antes colonizados, de outro. Dentre os principais autores deste movimento, devemos destacar Edward Said, Homi Bhabha, Gayatri Spivak, além de outros intelectuais como Albert Memmi e Franz Fanon. Sobre os estudos pós-coloniais, Costa e Grosfoguel (2016) afirmam:

[...] [Stuart] Hall secundariza a tentativa de uma explicação temporal em favor de uma explicação que enxerga o pós-colonial como uma abordagem crítica que se propõe a superar a crise de compreensão produzida pela incapacidade de antigas teorias e categorias de explicar o mundo. O "pós" do pós-colonial não 
significa que os efeitos do domínio colonial foram suspensos no momento em que concluiu o domínio territorial sob uma colônia. Ao contrário, os conflitos de poder e os regimes de poder-saber continuaram e continuam nas chamadas nações pós-coloniais. Diante disso, na resposta de Hall, o que será distintivo no pós-colonialismo será a capacidade de fazer uma releitura da colonização, bem como o tempo presente a partir de uma escrita descentrada, da diáspora; ou ainda global, das grandes narrativas imperiais do passado, que estiveram centradas na nação. (COSTA; GROSFOGUEL, 2016, p. 15)

Como principal contribuição destes autores está o questionamento aos estudos sobre a colônia produzidos por pensadores europeus e a identificação do olhar colonizador/colonizado de muitos destes autores que, em suas descrições, análises e formulações conceituais constroem um Outro que, em grande parte dos casos, pouco tem a ver com a realidade deste outro, pois remete mesmo às percepções do colonizador sobre si mesmo em oposição a um Outro que imagina. Um exemplo fundamental é o estudo de Said sobre a criação do Oriente pelo Ocidente: como demonstra o autor, o Oriente nada mais é do que um conjunto de ideias do colonizador que homogeiniza um grupo de sociedades sob a categoria Oriente, desconsiderando, nesta categorização, as especificidades de cada uma delas e, mais importante, criando um sistema binário ${ }^{1}$ em que, na construção do Oriente, configura-se o mesmo como um Outro que se opõe, sempre em posição inferiorizada, ao Ocidente. Este último, superior em essência, tem como missão dominá-lo, entendê-lo e, parte central do processo, explicar este Oriente para o próprio oriental, que seria incapaz de se compreender, ou melhor, que precisa mesmo ser ensinado sobre aquilo que 0 ocidental definiu como seu ser. Esta certeza da superioridade é produtiva e envolve uma série de campos do conhecimento: 
Portanto, o Orientalismo não é um simples tema ou campo político refletido passivamente pela cultura, pela erudição ou pelas instituições; nem é uma grande e difusa coletânea de textos sobre o Oriente; nem é representativo ou expressivo de alguma execrável trama imperialista "ocidental" para oprimir o mundo "oriental". É antes a distribuição de consciência geopolítica em textos estéticos, eruditos, econômicos, sociológicos, históricos e filológicos; é a elaboração não só de uma distinção geográfica básica (o mundo é composto de duas metades desiguais, o Oriente e o Ocidente), mas também de toda uma série de "interesses" que, por meios como a descoberta erudita, a reconstrução filológica, a análise psicológica, a descrição paisagística e sociológica, o Orientalismo não só cria, mas igualmente mantém; é, mais do que expressa, uma certa vontade ou intenção de compreender, em alguns casos controlar, manipular e até incorporar o que é um mundo manifestamente diferente (ou alternativo e novo); [...] $\mathrm{Na}$ verdade, o meu argumento real é que o Orientalismo é - e não apenas representa uma dimensão considerável da moderna cultura político-intelectual e, como tal, tem menos a ver com o Oriente do que com o "nosso" mundo. (SAID, 2007, p. 40/1, grifos no original)

Said (2007) demonstra ainda que este conjunto de conhecimentos sobre o Outro influencia o mesmo que também utiliza as categorias do colonizador para se constituir como ser, sendo esta uma das facetas mais perversas da colonização. Como demonstram ainda Albert Memmi e Frantz Fanon, existe um processo dialógico de constituição destes seres, colonizadores e colonizados, que só existem em relação. O colonizador, como já indicado, é constituído como o superior em oposição ao colonizado, que sendo o Outro inferior, ainda experimentaria uma inveja e desejo de ser algo que nunca poderá alcançar. O interessante deste movimento de produção do Outro é que ele envolve não apenas categorias psicológicas, mas todo um aparato conceitual que cobre todas as áreas da vida 
social. Uma série de binarismos é, então, constituído sempre posicionando o colonizador no lado positivo².

Apesar de seu potencial crítico e de se tornar um marco nas teorias sobre sociedades colonizadas, a reflexão póscolonial também foi ela alvo de questionamentos. De um lado, por não refletir e dialogar com a situação nas colônias latino-americanas e, especialmente, por realizar uma crítica que permanece utilizando os conceitos formulados pelo colonizador em suas reflexões, às teorias pós-coloniais apresentou-se a crítica decolonial, que visa ainda descolonizar a produção intelectual e as ideias, inverter o olhar das análises provincializando a Europa (giro decolonial) e localizar na "descoberta" das Américas a possibilidade mesmo de existência da modernidade europeia. De acordo com Costa e Grosfoguel (2016, p. 17):

Localizar o início do "sistema-mundo capitalista/patriarcal/cristão/moderno/colonial europeu" em 1492 tem repercussões significativas para os teóricos da decolonialidade. A mais evidente é o entendimento que a modernidade não foi um projeto gestado no interior da Europa a partir da Reforma, da Ilustração e da Revolução Industrial, às quais o colonialismo se adicionou. Contrariamente a essa interpretação que enxerga a Europa como um contêiner - no qual todas as características e os traços positivos descritos como modernos se encontrariam no interior da própria Europa -, argumenta-se que o colonialismo foi a condição sine qua non de formação não apenas da Europa, mas da própria modernidade. Em outras palavras, sem colonialismo não haveria modernidade, conforme fora articulado na obra de Enrique Dussel (1994). A partir dessa formulação tornou-se evidente a centralidade do conceito de colonialidade do poder, entendido como a ideia de que a raça e o racismo se constituem como princípios organizadores da acumulação de capital em escala mundial e das relações de poder do sistema-mundo (Wallerstein, 1990: 289). Dentro desse novo sistema-mundo, a diferença entre conquistadores e conquistados foi codificada a partir da ideia de raça (Wallerstein 1983; 1992: 206- 208; Quijano, 
2005: 106). Esse padrão de poder não se restringiu ao controle do trabalho, mas envolveu também o controle do Estado e de suas instituições, bem como a produção do conhecimento.

O principal expoente da teoria decolonial é Aníbal Quijano que desenvolve, junto ao grupo modernidade/colonialidade, não apenas o conceito de "colonialidade do poder", mas também o de "colonialidade do saber", destacando a produção do conhecimento como uma das armas mais fundamentais para a manutenção do poder pelos europeus, pois, como aponta Porto-Gonçalves (2005, p. 3), "A Colonialidade do Saber nos revela, ainda, que, para além do legado de desigualdade e injustiça sociais profundos do colonialismo e do imperialismo, já assinalados pela teoria da dependência e outras, há um legado epistemológico do eurocentrismo que nos impede de compreender o mundo a partir do próprio mundo em que vivemos e das epistemes que lhes são próprias".

Além das questões acima apresentadas, Quijano fornece centralidade ao conceito de raça como fundamental para a compreensão da constituição do capitalismo que ao definir os Outros como seres racializados, em oposição ao branco europeu que não possui uma raça, qualifica este último como o lócus inquestionável da autoridade e dos privilégios. Este processo de formulação do Outro se dá, como já mencionado, por meio de um conjunto de conceitos e formulações binárias que oprimem todas as sociedades compostas por não-brancos europeus, sendo a noção de raça aquela que, para Quijano, estrutura estas relações, pois

[...] a ideia de raça foi uma maneira de outorgar legitimidade às relações de dominação impostas pela conquista. A posterior constituição da Europa como nova identidade da América e a expansão do colonialismo europeu conduziram à elaboração da perspectiva eurocêntrica do conhecimento e 
com la à elaboração teórica da ideia de raça como naturalização dessas relações coloniais de dominação entre europeus e não-europeus. [...] os povos conquistados e dominados foram postos numa situação natural de inferioridade, e consequentemente também seus traços fenotípicos, bem como suas descobertas mentais e culturais (QUIJANO, 2005, p. 118).

Assim, a hipótese apresentada neste texto é a de que a noção de moda é mais uma das formulações eurocêntricas constituídas neste processo de colonialidade e inferiorização dos povos não europeus. Nos debruçaremos sobre este tema na próxima seção.

\section{Moda e colonialidade: vestuário, individualidade e mudança como instrumentos coloniais de poder}

Podemos considerar as crítica às perspectivas que tomam a moda como um "privilégio" do Ocidente como recentes, sendo possível localizar os primeiros trabalhos neste sentido em meados dos anos 1990, quando os estudos etnográficos sobre vestuário começam a questionar essa perspectiva exclusivista sobre a moda. Allman (2004, p. 2), ao discutir este tipo de abordagem acadêmica sobre a moda no contexto das análises sobre o vestuário na África, apresenta ainda aquela que a ela se opôs mais recentemente, traçando, a partir desses dois paradigmas, duas linhagens de abordagens sobre a moda:

[...] two dominant paradigms [about fashion]: 1) a cultural studies or historical approach to fashion and 2) an anthropological or ethnographic approach to dress. The former has been especially concerned with Western fashion as a system (including production and distribution) tha has shifted across time and space, and hence is profoundly historical. It considers fashion to be an explicit manifestation of the rise of capitalism and 


\begin{abstract}
Western modernity. Ethnographic studies, on the other hand, have been concerned with dress more broadly [...]. Leading scholars of this approach, like Ruth Barnes and Joanne Eicher have insisted that fashion is not a dress system specific to the West and their work has consistently sought to liberate the idea of "fashion" from the theoretical clutches of Western modernity. [...] Treating fashion as a marker of civilization, with all its attendant attributes, is the reason why fashion has been excluded from the repertoires of non-western cultures.Other codes of clothing behavior are relegated to the realm of costume wich, as "pre-civilised" behavior, is characterised in opposition to fashion, an unchanging, fixed by social status, and group-oriented.
\end{abstract}

A citação acima sintetiza muitos dos elementos que desejamos trazer para a discussão da moda em sociedades colonizadas e, especialmente, para as abordagens sobre a moda no Brasil. A intervenção etnográfica nos estudos sobre moda problematiza este conceito e busca inserir os povos não ocidentais dentro de um sistema de produção do vestuário que antes era tido como apenas Ocidental. Em resumo, politiza-se o conceito de moda quando aplicado às análises históricas, culturais e sociais sobre a moda, localizando os efeitos sociopolíticos de uma abordagem que busca afirmar não haver moda em sociedades fora do Ocidentais, onde incluímos o Brasil.

O olhar sobre a moda como apanágio do Ocidente, de sua capacidade de se individualizar e enfrentar as tradições, de se modernizar enfim, precisa ser desconstruída, centralmente por meio daquilo que denomina-se giro decolonial, ou seja, olhar a Europa não mais como o centro do mundo moderno ou como a própria modernidade e inserindo-a na história das demais civilizações como parte, não como motor. Deve-se assumir que o posicionamento da Europa no centro da produção epistêmica é parte da própria colonialidade do saber, pois esta visão sobre a centralidade da Europa é parte do construto eurocêntrico do 
conhecimento ou da geopolítica do conhecimento, como aponta Walter Mignolo e que, dentre muitas violências, inclui a construção do Outro não-Ocidental como inferior.

O problema da colonialidade do saber é um dos mais recorrentes dentro das discussões do M/C [grupo modernidade/colonialidade] e está diretamente associado àquilo que Mignolo (2002) chamou de "diferença colonial e geopolítica do conhecimento". Sendo paralela à própria geopolítica da economia, a noção de violência epistêmica elaborada por Foucault tornou-se insuficiente para captar o silêncio oriundo do racismo epistêmico (MaldonadoTorres, 2008) ou a negação da alteridade epistêmica (Castro-Gómez, 2005b). Para Castro-Gómez, a noção de Foucault "deve ser ampliada para o âmbito de macroestruturas de longa duração (Braudel/Wallerstein), de tal maneira que permita visualizar o problema da "invenção do outro" de uma perspectiva geopolítica" (Castro-Gómez, 2005a, p. 4). O que Foucault não conseguiu capturar em sua denúncia foi o eurocentrismo e o colonialismo, duas faces da mesma moeda. O eurocentrismo é uma lógica fundamental para a reprodução da colonialidade do saber [...] (BALLESTRIN, 2013, p. 103).

Como decorrência, toda o conjunto de conceitos associados à modernidade também devem ser "girados" e, considero dentre eles, o de moda. Para realizar tal processo, devemos compreender que a moda é um conceito inserido no projeto da colonialidade que ignora a história e a mudança entre os povos não ocidentais, ou melhor, que entende que estes povos estão presos em suas tradições culturais. Com "presos", incluímos a ideia do colonizador de que as sociedades não ocidentais vivem imersas em um tempo circular contínuo que não se abriria para mudanças. Este tipo de percepção, como decorrência, estabelece e agudiza, como apontado na introdução, a percepção evolucionista de que os povos não ocidentais estão atrasados, não mudam e que nunca alcançarão o status do colonizador. 
Contudo, é tema já largamente debatido na antropologia a percepção eurocêntrica sobre o tempo e a cultura das sociedades fora do centro. Como destaca Sahlins (2003), todo sistema cultural está em permanente diálogo com a práxis e, em razão desta interação, este sistema se reavalia a todo tempo. Este processo provoca mudanças em diversos níveis, alterações estas que um olhar eurocentrado racista pode optar não perceber. Para Sahlins (2003, p. 9):

[...] na existência e na interação dual entre a ordem cultural enquanto constituída na sociedade e enquanto vivenciada pelas pessoas: a estrutura na convenção e na ação, enquanto virtualidade e enquanto realidade. Os homens em seus projetos práticos e em seus arranjos sociais, informados por significados de coisas e de pessoas, submetem as categorias culturais a riscos empíricos. Na medida em que o simbólico é, deste modo, pragmática, o sistema é, no tempo, a síntese da reprodução e da variação.

Assim, é possível afirmar que em contato com outras culturas ou ainda por riscos diversos colocados à determinada cultura por suas próprias ações e relações, a mesma está exposta à mudança cultural. Todos os aspectos da sociedade, desta maneira, estão passíveis de alterações e é inevitável entender que o vestuário está incluído neste processo. Desta maneira, há mudanças na vestimenta dos povos, ainda que elas possam não estar motivadas pelo movimento de imitação-distinção ou que estejam perceptíveis a olhos desinteressados.

É evidente que não ignoramos que ocorre um processo específico na Europa diretamente vinculado à Revolução Industrial europeia e que este movimento tem uma relação íntima com a indústria têxtil e a necessidade de renovação dos vestuários. Contudo, não devemos ignorar também que este processo só ocorre em razão das relações com as sociedades que foram colonizadas, seja pelo acesso a 
matéria-prima, seja pela influência das modas destes locais sobre a moda europeia e vice-versa. O contato entre as culturas provoca alterações em ambas e seria ingênuo - ou maldade - imaginar que as sociedades não ocidentais estavam totalmente desconectadas destas relações. Nem que fossem cegas.

Consideramos ser muito mais provável que o colonizador tenha sido incapaz - ou deliberadamente não desejou registrar apropriadamente as alterações presentes no vestuário não ocidental, assim como as razões destas mudanças, estejam elas relacionadas a um processo de imitação-distinção ou não. É muito mais fácil capturar as novidades produzidas nas colônias e se apropriar das mesmas como criação própria e acusar os produtores originais de cópia ou de incapacidade de criação, mudança, moda. O processo é simples: primeiro, desestrutura-se a autoestima e o padrão de valores de um povo por meio de desqualificações que tem na (falsa) ciência racial seu apoio sociohistórico e biológico; em seguida, desloca-se o(s) sentido(s) e significado(s) que só podem ser analisados em relação aos demais sentidos e significados do sistema de referência do povo, isolando-o e esvaziando-o; por fim, constrói-se uma narrativa de ressignificação destes valores a partir de um olhar eurocentrado que é vendido como os sentidos e significados aceitáveis, corretos, belos.

A noção de raça é, assim, fundamental para se compreender também qualquer abordagem que se realize sobre o vestuário em seu sentido histórico. É importante retomar a discussão sobre raça, mesmo que brevemente. Ainda que o autor decolonial Anibal Quijano tenha um papel central na construção de uma crítica ao modelo colonial a partir da noção de raça, diversos autores pós-coloniais já haviam ressaltado a centralidade da noção para a compreensão do sistema mundo capitalista/colonial. No que 
se refere à moda, é interessante trazer a discussão de Fanon (2011) sobre a questão do racismo em sua relação com a cultura. O autor aponta, logo no início de seu texto "Racismo e Cultura" que o objeto do racismo são as formas de existir. Assim, não se trata apenas ou essencialmente de um ataque ao elemento cor de pele ou ao fenótipo, de modo mais amplo. O racismo se trata de uma desvalorização sistematizada de todos os elementos que caracterizam um povo e de seu aprisionamento em um sistema cultural construído, em geral, a partir do olhar do próprio colonizador.

No entanto, a implantação do regime colonial não traz consigo a morte da cultura autóctone. Pelo contrário, a observação histórica diz-nos que o objectivo procurado é mais uma agonia continuada do que um desaparecimento total da cultura preexistente. Esta cultura, outrora viva e aberta ao futuro, fecha-se, aprisionada no estatuto colonial, estrangulada pela carga da opressão. Presente e simultaneamente mumificada, depõe contra os seus membros. Com efeito, define-os sem apelo. A mumificação cultural leva a uma mumificação do pensamento individual. A apatia tão universalmente apontada aos povos coloniais não é mais do que a consequência lógica desta operação. A acusação de inércia que constantemente se faz ao "indígena" é o cúmulo da má-fé. Como se fosse possível que um homem evoluísse de modo diferente que não no quadro de uma cultura que o reconhece e que ele decide assumir. É assim que se assiste à implantação de organismos arcaicos, inertes, que funcionam sob a vigilância do opressor e decalcados caricaturalmente sobre instituições outrora fecundas... (FANON, 2011, p. 276).

Nesse sentido, o vestuário, como os demais sentidos e significados propostos por um povo são não apenas desqualificados, mas também aprisionados em um sistema denominado pelo colonizador de "cultura" de tal povo. Esta cultura nada mais é do que um conjunto de elementos selecionados pelo colonizador como relevantes e que, por 
meio do processo colonial, se tornam referência de valor até mesmo para o povo que desenvolveu tais padrões, como também aponta Said (2007). A noção de raça é, neste sentido, aquela que autoriza o branco a desqualificar os sentidos e significados produzidos pelos diversos povos nãobrancos do mundo, o que inclui suas vestimentas e, porque não afirmar, sua moda.

Neste ponto do artigo, é quase inevitável perguntar a esta autora qual seria, enfim, a definição de moda com a qual trabalha. Pois bem, entendemos que a moda é uma forma de se relacionar com o vestuário, dentre muitas outras, devendo ser estudada como o que de fato ela é: uma das maneiras de se lidar com o vestuário não sendo melhor ou mais surpreendente que qualquer outra, ainda que tenha sido objeto de mais estudo, mais uma das facetas da colonialidade do saber. Neste sentido, o vestuário incorpora a moda, uma vez que esta última existe apenas como uma relação social que se estabelece com o primeiro. Assim, em alguma medida, nos alinhamos com Tulloch (2010, p. 279) quando a autora opta pelo termo dress porque ele "[...] incorporates all aspects of the subject fashion, style, production, consumption, textiles, and beauty regimes in which the group was interested." Em alguma medida porque acreditamos que, atualmente, inseridos que estamos no capitalismo periférico, o termo moda é o mais adequado para denominar as relações com o vestuário mesmo nas sociedades antes colonizadas. Considerando tal reflexão, talvez o mais adequado, então, é que a moda seja definida como formas de se relacionar com o vestuário sem a exclusividade que é fornecida ao modo europeu de fazê-lo, incorporando, deste modo, os modos de vestir entendidos como costume ou indumentária também como moda. 
Com tal abordagem, desejamos inserir a moda, como forma de relação com o vestuário vinculada especialmente com o Renascimento Europeu, no mesmo nível sociocultural das demais formas de se relacionar com o vestuário, retirando o potencial evolucionista do termo que entende que as sociedades não ocidentais se utilizam do vestuário de uma maneira tradicional ou costumeira, ou seja, que possuem costume ou indumentária. Consideramos ainda, desta maneira, que a mudança não é uma ação exclusiva da moda como forma de relação com o vestuário, ou seja, que em nenhuma medida as sociedades africanas, latinoamericanas, árabes e, em alguma medida, orientais e que antes forma colonizadas, em qualquer momento de suas histórias, estiveram atrasadas em seu modo de lidar com a vestimenta, mas sim que elas se relacionam de modo diferente com o vestuário, alterando-a de acordo com suas demandas socioculturais e políticas, de acordo com uma lógica própria que, em nenhuma medida, é atrasada ou não alcançou a lógica da moda ocidental, mesmo porque esta pode nunca ter sido sua finalidade, pois, como afirma ainda Sahlins (2004, p. 181), "[...] é também conhecimento geral na antropologia que o esquema 'racional' e 'objetivo' de qualquer grupo humano nunca é o único possível. Mesmo em condições materiais muito semelhantes, as ordens e finalidades culturais podem ser muito distintas".

Retomamos, assim, as discussões presentes na tese da autora defendida em 2015: a moda ou lógica da moda é uma forma de se lidar com o vestuário que dialoga com o sistema capitalista ocidental, nele está inserido e faz parte. De um lado, se espalhou como lógica aos demais setores da sociedade europeia e foi disseminado pelo mundo com o processo colonial como o funcionamento mais evoluído e correto de relação com o vestuário, momento em que todas as demais sociedades que não estabeleciam uma relação 
específica com o vestuário, como a individualização e a negação das tradições, foram colocadas à margem e consideradas inferiores e incapazes de se relacionar de uma maneira saudável - no sentido de são (saúde mental) mesmo - com o novo, com o tempo, com a roupa. De outro, retirou qualquer tipo de autoridade criativa à produção de vestuário das sociedades não ocidentais ou culturas à margem, que passam a ter suas criações apropriadas pelo centro e reeditadas ao gosto europeu que pode acusar às primeiras de imitadoras ou, quando não vê seu poder ameaçado, mencioná-las como idealizadoras de segunda categorias, ou seja, criadores que sequer foram capazes de perceber a inovação de suas criações, como aponta Said (2007), cabendo ao colonizador educá-las. O conceito de moda, enfim, contribui para segregar e desnivelar todas as sociedades do capitalismo periférico que por não possuir moda, têm, por princípio, uma relação errônea com as vestimentas e com o tempo.

Antes de encerrar as discussões, gostaria de apontar mais dois outros conceitos muito recorrentemente utilizados no discurso sobre moda, qual seja, o de exótico e o de étnico. Assim como atribuir moda ao Ocidente gera um desnivelamento, mesmo que não deliberado, do uso do vestuário entre os povos do centro para com aqueles das periferias do capitalismo, os termos exótico e étnico, são duas categorias associadas à cultura do Outro - e aqui é relevante acentuar que não se utilizam, senão circunstancialmente, estas noções a produtores dos grandes centros - com o objetivo de mumificar, utilizando o conceito de Fanon (2011), as formas de vestir não Ocidentais. Estes termos outrificam as culturas de maneira muito rápida e objetiva: com apenas uma palavra, desqualifica-se todo o referencial de um povo e homogeiniza-se/simplifica-se este mesmo povo em um mar de estranhamento junto com uma 
vastidão de outras sociedades. Basicamente, o exótico ou étnico é aquilo que o branco não é.

O exotismo é uma das formas desta simplificação. Partindo daí nenhuma confrontação cultural pode existir. Por um lado, há uma cultura na qual se reconhecem qualidade de dinamismo, de desenvolvimento, de profundidade. Uma cultura em movimento, em perpétua renovação. Frente a esta, encontram-se as características, curiosidades, coisas, nunca uma estrutura (FANON, 2011, p. 276).

Com este artigo me alinho, deste modo, aos teóricos póscoloniais que refletem sobre a moda em sociedades não ocidentais, especialmente na África e na diáspora, mas também aqueles que analisam a moda no "oriente" e nas colônias como um todo, buscando redefinir as abordagens sobre o vestuário fora dos grandes centros e incluem estas produções descentralizadas como moda, mesmo porque não haveria qualquer possibilidade de revolução industrial via indústria têxtil, e de moda, sem as colônias que a ela forneceram matéria-prima e mão de obra, direta ou indiretamente, como também demonstra o grupo colonialidade/modernidade (QUIJANO, 2005). Se a própria ocorrência da moda europeia depende da existência das colônias, é no mínimo sem nexo considerar a moda desconsiderando as relações nas ex-colônias com o vestuário. Deste modo, ao invés de trabalhar com a oposição "moda X costume", trabalharemos com a relação entre modas - como formas de se lidar com o vestuário -, ou seja, com as conexões e entrelaçamentos que são estabelecidas entre as diversas formas de se lidar com 0 vestuário a partir de diversos pontos nodais que serão tomados como referência para além da Europa. Assim, analisar qualquer elemento da moda na Europa obriga o pesquisador a avaliar a relação daquela moda com as periferias produtoras de outras modas, multiplicando os 
pontos de referência do olhar, descentralizando o centro e recolocando as sociedades antes colonizadas em posições diferenciadas daquelas impostas pelo colonizador, qual seja, imitadoras e desejosas de ser o centro. Encerramos, assim, com um trecho que, para nós [sic], define a abordagem sobre a moda que desejamos estabelecer de agora em diante:

Identity nots become identity (k)nots when entanglement replaces opposition and evolution as an organizing logic. Drawing on African diasporic theory, we propose a new (k) notty model to describe the entanglements of fashion. Knots take multiple forms, from the tangled fishing line hopelessly ruining the intended function of the thread, to the climber's knots constructed to guarantee safety and save lives, to the hangman's noose steeped in a history of oppressions and violence. Such knots rely upon tension and flexibility - both of which can reinforce or loosen knots, depending on their construction and constituent parts. The knot metaphor proves useful in theorizing the fashion subject. It provides a tensile image accommodating to intersectionality, multiple subjects positions, minding appearances and dialectical models by providing space to considerar connections and disconnections. In science and technology studies, knots and network concepts aid scholars through their ability to reveal the dynamic interplay between sociocultural actors and scientifics research in the formations of scientific facts. The knot allows us to follow shifting relationships as modeled in actor network theory, as Tulloch does, while also staying attuned to nodes that pop: the metaphor allows us to pay attention to the combination of material and discursive forces that come into play in considerations of appearance and style. At their most productive level, such knotty fashion subjects revela connections that otherwise might remain hiddens [...] (Kaiser; McCullough, 2010, p. 363/4).

\section{Notas}


1 Segato (2012) faz uma discussão sobre a questão de gênero a partir de uma perspectiva decolonial em que diferencia o sistema binário, característico da reflexão colonial, dos sistemas duais, presentes nas sociedades nãoocidentais ameríndias que estuda. Para a autora, a dualidade está presente nos sistemas classificatórios em diferentes sociedades, estabelecendo oposições que marcam diferenças hierárquicas, mas que são complementares. Contudo, a binarização ocidental tem como característica o desenvolvimento de uma fissura entre os opostos que deixam de se complementar e passam a se sobrepor, aprofundando as hierarquias que funcionam não por complementaridade, mas por opressão.

2 Aqui vale destacar mais uma vez o trabalho de Schucman (2012), pois a autora demonstra que a autoridade do colonizador, quando transferido para os contextos coloniais, produz oposições e fissuras entre os sujeitos da própria colônia. Assim, aquele que mais se aproxima do colonizador, os brancos no Brasil, se tornam o polo positivo no sistema binário local, seja esteticamente, seja moralmente, ou nos demais campos da vida social. Esta proximidade idealizada com o colonizador fornece a mesma autoridade ao sujeito branco para tornar os sujeitos nãobrancos em Outros e, assim como o colonizador, dominá-los.

\section{Referências}

ALLMAN, Jean. Fashioning Africa: Power and the Politics of dress. In.: ALLMAN, Jean (Org.). Fashioning Africa: Power and the politics of Dress. Bloomington: Indiana University Press, 2004;

BALLESTRIN, Luciana. América Latina e o giro decolonial. Rev. Bras. Ciênc. Polít., Brasília , n. 11, p. 89-117, Aug. 2013. Available from http://www.scielo.br/scielo.php?script=sci_arttext\&pid=S010333522013000200004\&lng=en\&nrm=iso. access on 22 Feb. 2019.

BERNARDINO-COSTA, Joaze; GROSFOGUEL, Ramón. Decolonialidade e perspectiva negra. Soc. estado., Brasília , v. 31 , n. 1 , p. 15-24, Apr. 2016 . Available from 
http://www.scielo.br/scielo.php?script=sci_arttext\&pid=S010269922016000100015\&lng=en\&nrm=iso. access on 16 Mar. 2019.

FANON, Frantz. Racismo e cultura. In.: SANCHES, Manuela Ribeiro (org.). Malhas que os impérios tecem $>$ textos anticoloniais, contextos pós-coloniais. Lisboa: Edições 70, 2011.

FREYRE, Gilbero. Sobrados e Mucambos. São Paulo: Global Editora, 2006.

QUIJANO, Anibal. Colonialidade do poder, Eurocentrismo e America Latina. In: Lander, Edgardo. (org.) A Colonialidade do Saber: eurocentrismo e ciências sociais. Perspectivas Latinoamericanas. Clacso, Consejo Latinoamericano de Ciências Socialies, Ciudad Autônoma de Buenos Aires, Argentina, 2005, pp.105-127.

RAINHO, Maria do Carmo Teixeira. A cidade e a moda: novas pretensões, novas distinções - Rio de Janeiro, século XIX, A. Brasília: Universidade de Brasília, 2002.

SAHLINS, Marshall. Introdução. In.: Ilhas de História. Rio de Janeiro: Zahar, 2003.

SAHLINS, Marshall. La pensée bourgeoise: a sociedade ocidental como cultura. In.: SAHLINS, Marshall. Cultura na Prática. Rio de Janeiro: Editora UFRJ, 2004.

SAID, Edward W. Orientalismo: o Oriente como invenção do Ocidente. São Paulo : Companhia das Letras, 2007.

SEGATO, Rita Laura. Gênero e colonialidade: em busca de chaves de leitura e de um vocabulário estratégico descolonial. Ecadernos ces [Online], 18 | 2012, colocado online no dia 01 dezembro 2012, consultado a 16 março 2019.

TULLOCH, Carol. Style-Fashion-Dress: from black to post-black. Fashion Theory: The Journal of Dress, Body \& Culture. Oxford: Berg Publichers, 2010. 